\title{
Coated pellets with delayed-release glucose for prevention of hypoglycemic episodes
}

\author{
DANA SABADKOVÁ ${ }^{1}$ \\ ALEŠ FRANC ${ }^{1 *}$ \\ JAN MUSELÍK ${ }^{1}$ \\ DAVID NEUMANN ${ }^{2}$ \\ ${ }^{1}$ Department of Pharmaceutics \\ Faculty of Pharmacy \\ University of Veterinary and \\ Pharmaceutical Sciences \\ 61200 Brno, Czech Republic \\ ${ }^{2}$ University Hospital \\ Department of Pediatrics \\ 50005 Hradec Králové \\ Czech Republic
}

Accepted December 17, 2015 Published online May 11, 2016

\begin{abstract}
Patients tend to prevent hypoglycemia by excessive saccharide intake leading to poorer glycemic control with potentially fatal consequences. This problem could be resolved by means of pellets with glucose release delayed by 120 $360 \mathrm{~min}$ as a compensation of the antidiabetic drug peak effect. No glucose is released before; hence there is no risk of hyperglycemia and secondary complications. The pellets contain glucose in combination with an osmotically active ingredient and are coated with an ethylcellulose dispersion, which forms an insoluble semipermeable membrane and ensures delayed release. The release of glucose was assessed using dissolution and high-performance liquid chromatography. Dissolution profiles indicated the possibility of achieving the requested lag time using a combination of adequate compositions and coating concentrations. Lag times of 60, 240 and 360 min were achieved. The sample containing carboxymethyl starch was found to be most suitable for the intent of this work.
\end{abstract}

Keywords: hypoglycemia, diabetes mellitus, pellets, delayed release, glucose, pellet evaluation

Hypoglycemia is a common, dangerous and usually unpredictable complication in diabetes mellitus therapy. It can be defined as the occurrence of a variety of symptoms associated with plasma glucose concentration lowered under $3.9 \mathrm{mmol} / 1(1,2)$. If untreated, hypoglycemia can lead to seizures, coma, and death (3). Hypoglycemia frequently develops as a result of misbalance between the effect of insulin or peroral antidiabetics and food intake. Hypoglycemia during sport activities, nocturnal hypoglycemia and hypoglycemia caused by irregular diet are typical examples of such situations.

Children and adolescent are more vulnerable to hypoglycemia than adults. Many factors induce the risk of hypoglycemia in young patients. Children and adolescent tend to eat erratically and perform physical activity irregularly, making it difficult to ensure optimal glucose levels during the day. Moreover, hypoglycemic symptoms may be difficult for children to recognize and verbalize, which can lead to longer delays in treatment and in-

\footnotetext{
*Correspondence; e-mail: franca@vfu.cz
} 
creased duration and depth of the episode. In addition, repeated hypoglycemic events can reduce the responses of the organism to subsequent hypoglycemic episodes, leading to hypoglycemia unawareness - the onset of hypoglycemia before the appearance of warning symptoms (4). After undergoing a severe hypoglycemic episode, children and parents try to prevent its recurrence by excessive intake of saccharides, which keeps blood glucose above the recommended values. Glycemic control is therefore poorer, which may be even more pernicious to patient health than a hypoglycemic episode (5). Formulation of food supplements with delayed release of sugar seems to be a very promising solution to this problem. Sugar is released after a predetermined lag time, during the peak activity of an antidiabetic drug. According to diabetological practice, appropriate lag times should be between 120-360 min, depending on the administered antidiabetic drug.

The aim of this work was to develop and evaluate a dietary supplement with controlled release of carbohydrates as possible prevention of hypoglycemic episodes due to the imbalance between the effect of antidiabetic drugs and food intake. Such a dietary supplement comprises a multiparticulate delayed-release dosage form (pellets) containing a mixture of glucose and disintegrants or osmotically active substances coated with a semipermeable membrane. This allows water diffusion and consequent activation of the core excipients, leading to core swelling and increase in osmotic pressure. Therefore, disruptions (ruptures or punctures) are formed in the pellet coating and glucose release starts after a specific lag time (6). Pellets were chosen as a dosage form due to their small size that enables easy administration even to pediatric patients. Pellet cores were prepared using extrusion-spheronization and were subsequently coated in a Wurster-type fluid bed coating unit. Both pellet cores and coated pellets were evaluated for their physical characteristics. Glucose release from coated pellets was determined by dissolution and analyzed by high-performance liquid chromatography. The developed compositions were originally extruded through a $1.0 \mathrm{~mm}$ mesh screen (6). Since the dietary supplement would be mainly intended for administration to pediatric patients, the current target was to prepare pellets with diameters reduced to $0.8 \mathrm{~mm}$ and to assess the characteristics and glucose release of such pellets.

\section{EXPERIMENTAL}

\section{Materials}

Glucose anhydrous was obtained from Dr. Kulich Pharma, Czech Republic. Microcrystalline cellulose (Avicel ${ }^{\circledR}$ PH 101), a mixture of microcrystalline cellulose and carboxymethylcellulose sodium (Avicel ${ }^{\circledR}$ RC 591), and croscarmellose sodium (Ac-Di-Sol ${ }^{\circledR}$ ) were purchased from FMC Biopolymer, Belgium. Polyethylene glycol 6000 was acquired from Merck Schuchardt OHG, Germany. Carboxymethyl starch (Vivastar ${ }^{\circledR}$ P 5000) was bought from JRS Pharma, Germany. Aqueous ethylcellulose dispersion (Surelease ${ }^{\circledR}$ type B NF) was obtained from Colorcon, USA.

\section{Preparation of cores}

Pellet cores were prepared by extrusion-spheronization. Details on the composition of the prepared formulations are given in Table I. Dry ingredients were passed through a $250 \mu \mathrm{m}$ sieve and stirred in a blender (TEFAL Kaleo, Type: 676210, France) for one minute 
Table I. Compositions of pellets

\begin{tabular}{lcccc}
\hline \multirow{2}{*}{ Compound } & \multicolumn{4}{c}{ Concentration $(\%, \mathrm{~m} / \mathrm{m})$} \\
\cline { 2 - 5 } & ADS & RC & PEG & CMS \\
\hline Glucose & 80.0 & 75.0 & 75.0 & 80.0 \\
Avicel PH 101 & 15.0 & - & - & 15.0 \\
Ac-Di-Sol & 5.0 & - & - & - \\
Avicel RC 591 & - & 25.0 & - & - \\
PEG 6000 & - & - & 25.0 & - \\
CMS & - & - & - & 5.0 \\
Water $^{\mathrm{a}}$ & 43.0 & 33.0 & 12.0 & 15.0 \\
\hline
\end{tabular}

a evaporates during the drying process

at a speed of $400 \mathrm{rpm}$. Water was added and the mixture was stirred for another minute to ensure uniform distribution of the moistening agent in the composition. The resulting plastic mass was extruded through a mesh screen of $0.8 \mathrm{~mm}$ diameter using a screw radial extruder (Pharmex 35T, Wyss \& Probst Eng, Germany). The extruded cylinders were collected and placed into a $230 \mathrm{~mm}$ cross-hatch plate spheronizer (Pharmex 35T, Wyss \& Probst Eng, Germany). The cores were produced applying a rotation speed of $1000 \mathrm{rpm}$ for 5 minutes. The resulting cores were dried in a hot air dryer (Horo, Type 38A, Germany) at $60{ }^{\circ} \mathrm{C}$ for 2 hours.

\section{Coating of cores}

The cores were coated with $15 \%$ aqueous ethylcellulose dispersion (Surelease ${ }^{\circledR}$ type B NF) in a Wurster-type fluid bed coating unit (M-100, Medipo, Czech Republic) under the following conditions: spray nozzle diameter $1.0 \mathrm{~mm}$, atomization pressure $1.4 \mathrm{bar}$ and inlet air temperature $65^{\circ} \mathrm{C}$. The final coating represented $12.5,25$ or $50 \%$ of the total pellet mass, resulting in three different samples for each composition. The pellets were dried in a hot air dryer (Horo, Type 38A, Germany) at $60^{\circ} \mathrm{C}$ for 4 hours.

\section{Evaluation of cores and coated pellets}

Flow properties, i.e., flowability, bulk and tapped densities, Hausner ratio (HR), and Carr compressibility index (CI) were evaluated according to the European Pharmacopoeia. Flowability was assessed using a flow funnel with a $10 \mathrm{~mm}$ nozzle diameter. HR and CI were calculated from the values of bulk and tapped densities. Particle size and size distribution were evaluated by a sieve analysis using a set of stainless steel sieves with apertures ranging from 0.125 to $2.000 \mathrm{~mm}$ (AS 200 basic, Retsch GmbH \& Co. KG, Germany). Pycnometric density was determined in a helium pycnometer (Porotec, Pycnomatic-ATC, Germany). Sphericity factor and aspect ratio were analyzed in 100 particles using an optical microscope (Nikon SMZ 1500, Japan) equipped with a charged coupled device camera (Nikon Alphaphot-2, Japan) and image analysis (Leco Instruments, Leco IA 32, USA). Core friability was measured by rotating in a stainless steel drum of a friabilator (Erweka TAR 
10, Germany) for $10 \mathrm{~min}$ at $20 \mathrm{rpm}$ with addition of 200 glass beads with a $4 \mathrm{~mm}$ diameter. Core moisture content was assayed in a halogen moisture analyzer (Mettler Toledo, HX204, Switzerland) under the following conditions: standard drying program, drying temperature $105^{\circ} \mathrm{C}$, switch-off criterion $1 \mathrm{mg} / 50 \mathrm{~s}$. Scanning electron microscopy (SEM) images of cores and coated pellets were taken to examine the pellet shape and surface using a scanning electron microscope (JCM-6000 NeoScope ${ }^{\mathrm{TM}}$ Benchtop SEM, JEOL, USA). Coating thickness was determined from SEM images of cut pellets as the mean diameter of four measurements. To obtain cut samples, single pellets were captured with a pair of tweezers, placed on a hard surface and cut transversely using a razor blade.

\section{Determination of drug release}

Samples of coated pellets were placed into $900 \mathrm{~mL}$ of water heated to $37 \pm 0.5^{\circ} \mathrm{C}$ for dissolution studies employing a dissolution apparatus (Sotax AT-7, Switzerland), basket method at $100 \mathrm{rpm}$. The samples were withdrawn after 60, 120, 240, 360, 540, and $720 \mathrm{~min}-$ utes and subsequently analyzed for glucose content using high-performance liquid chromatography with an evaporative light scattering detector. Each experiment was performed twice and the results are expressed as mean values \pm standard deviation of the active substance in \% dissolved at the given sampling time.

\section{RESULTS AND DISCUSSION}

\section{Evaluation of cores}

Pellet cores should have appropriate mechanical and flow properties to enable subsequent coating. Produced cores were therefore tested to discern the flow properties, sphericity, aspect ratio, particle size distribution, moisture content, and friability (Table II). Flow character of the cores can be considered excellent when comparing the values of HR

Table II. Physical characteristics of cores and pellets with $50 \%$ coating

\begin{tabular}{lccccccccccc}
\hline Sample & $F w$ & $S$ & $A R$ & $D_{\mathrm{B}}$ & $D_{\mathrm{T}}$ & $D_{\mathrm{P}}$ & $H R$ & $C I$ & $M$ & $F r$ & $C T$ \\
\hline ADS & 10.44 & 0.90 & 1.64 & 0.68 & 0.74 & 1.49 & 1.09 & 8.11 & 2.46 & 1.90 & N/A \\
RC & 10.46 & 0.88 & 1.71 & 0.75 & 0.81 & 1.50 & 1.08 & 7.41 & 1.03 & 0.24 & N/A \\
PEG & 10.59 & 0.83 & 1.85 & 0.71 & 0.75 & 1.43 & 1.06 & 5.33 & 5.19 & 1.12 & N/A \\
CMS & 10.50 & 0.83 & 1.89 & 0.77 & 0.82 & 1.51 & 1.06 & 6.10 & 1.18 & 0.51 & N/A \\
ADS_50 & 11.68 & 0.91 & 1.60 & 0.70 & 0.74 & 1.23 & 1.06 & 5.41 & N/A & N/A & 70.1 \\
RC_50 & 11.23 & 0.91 & 1.62 & 0.74 & 0.78 & 1.27 & 1.05 & 5.13 & N/A & N/A & 80.5 \\
PEG_50 & 11.09 & 0.89 & 1.80 & 0.74 & 0.76 & 1.21 & 1.02 & 2.63 & N/A & N/A & 66.0 \\
CMS_50 & 11.06 & 0.83 & 1.81 & 0.72 & 0.76 & 1.26 & 1.06 & 5.26 & N/A & N/A & 75.6 \\
\hline
\end{tabular}

$F w$ - flow rate $\left(\mathrm{g} \mathrm{s}^{-1}\right) ; S$ - sphericity factor; $A R$ - aspect ratio; $D_{\mathrm{B}}$ - bulk density $\left(\mathrm{g} \mathrm{mL}^{-1}\right) ; D_{\mathrm{T}}$ - tapped density $(\mathrm{g}$ $\left.\mathrm{mL}^{-1}\right) ; D_{\mathrm{P}}$ - pycnometric density $\left(\mathrm{g} \mathrm{mL}^{-1}\right) ; H R$ - Hausner ratio; $C I$ - compressibility index (\%); $M$ - moisture $(\%) ; F r$ - friability (\%), CT - coating thickness $(\mu \mathrm{m})$.

N/A - not applicable 
and CI with the pharmacopoeial limits (7). The finding was also confirmed by the results of flowability evaluation. Flowability was higher than $9.5 \mathrm{~g} \mathrm{~s}^{-1}$ in all samples, which indicates excellent pellet flow properties according to the literature (8). The values of pycnometric densities were very similar and ranged from 1.43 to $1.51 \mathrm{~g} \mathrm{~mL}^{-1}$. Results of the sieve analysis (Fig. 1a) revealed that the $0.50-0.80 \mathrm{~mm}$ fraction was most frequent in ADS, CMS, and PEG samples. The $0.80-1.00 \mathrm{~mm}$ fraction was most frequent in sample RC. The suggested sphericity factor and aspect ratio for pellets is $\geq 0.8$ and $\leq 1.2$, respectively $(9,10)$. Although the sphericity factor met the criterion in all samples, the aspect ratio values showed that the core shape was not completely ideal, which was also verified by SEM images (Fig. 2). However, smaller spherical shape does not necessarily mean a complication since even smaller particles with more irregular shape are commonly used in pharmaceutical technology (11). Core moisture content was low and ranged from 1.03 to $5.19 \%$. It is congruous to keep the residual moisture values as low as possible since higher moisture content might have an adverse effect on the batch-to-batch uniformity and reproducibility (12). When taking the value of $1.7 \%$ as the friability limit for cores intended for subsequent coating, friability of RC, PEG and CMS samples was satisfactory (13). The ADS sample exceeded this limit only moderately and could thus be used for coating.
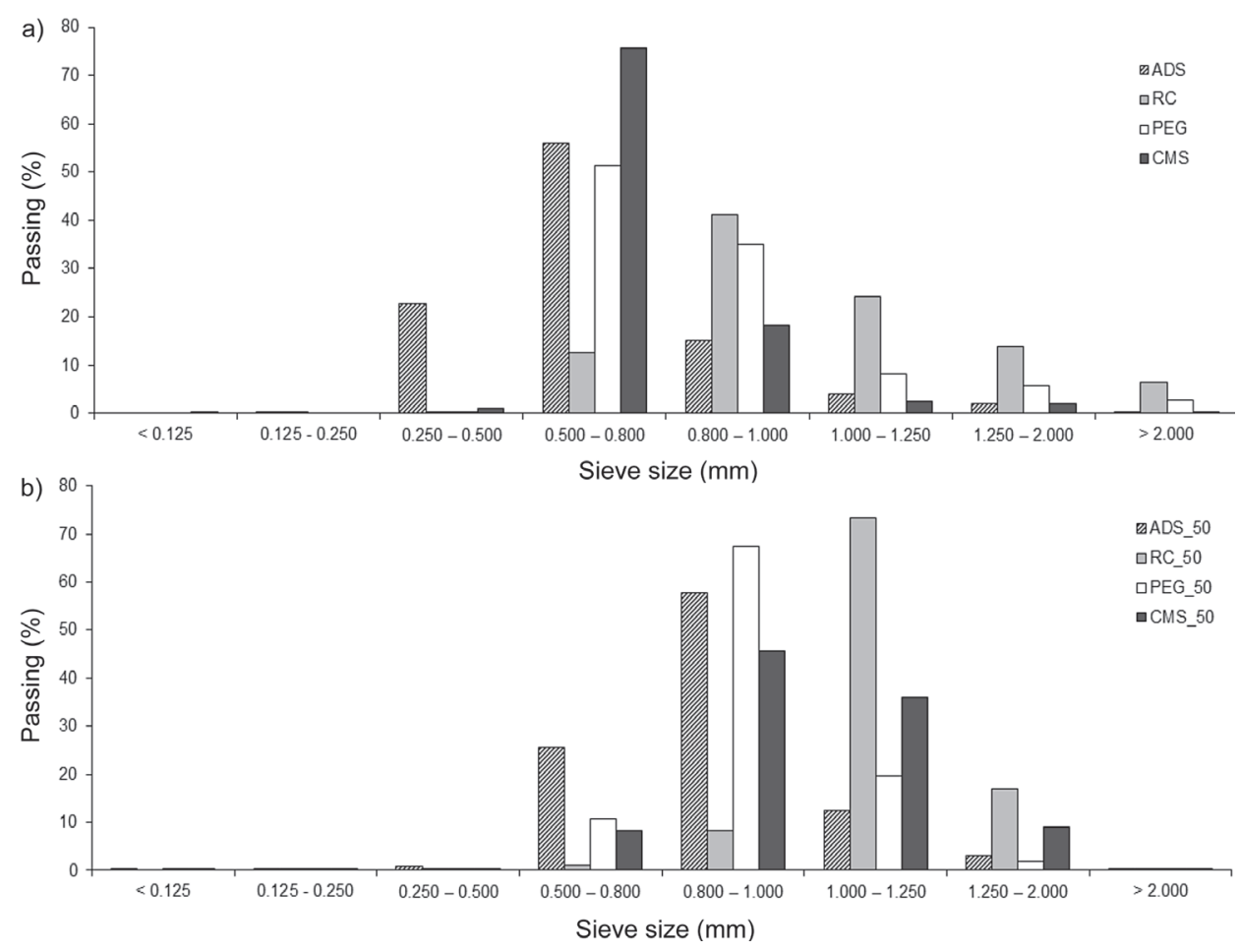

Fig. 1. Sieve analysis of: a) cores and b) coated pellets (50\% coating). Hatched column represents the ADS sample, light grey column represents the RC sample, white column represents the PEG sample and dark grey column represents the CMS sample. 


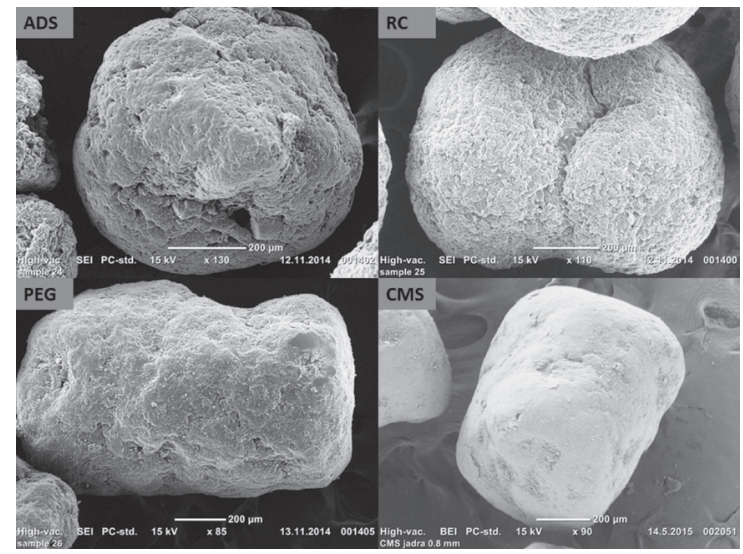

Fig. 2. SEM images of cores.

\section{Evaluation of coated pellets}

Pellets were evaluated again after the coating process and the evaluation results of cores and coated pellets were compared (Table II). Properties were evaluated only in pellets with $50 \%$ coating concentration since only small amounts of samples with 12.5 and $25 \%$ coating concentration were removed for the dissolution study during the coating process.

Coating did not have much effect on pellet shape, with sphericity and aspect ratio values almost the same as in cores. Pycnometric density was reduced in coated samples. During the coating process, density generally decreased with increasing the amount of Surelease ${ }^{\circledR}$ coating (14). Flowability was higher in coated samples as the coating probably lowered the friction and electrostatic forces between individual pellet particles. Moreover, coating sleeked the pellet surface, as can be seen when comparing SEM images of cores and coated pellets (Fig. 2 and 3). It is evident that the core structure was porous and the surface was smoother after the coating process. The coating layer of the individual samples is shown in the cut pellet images (Fig. 4). Flow character remained excellent with lower values of CI. Regarding particle size, it is evident that coating caused pellet enlargement and the major fraction drifted from $0.50-0.80$ to $0.80-1.00 \mathrm{~mm}$ for ADS, PEG and CMS samples. The major fraction for sample RC was shifted to $1.00-1.25 \mathrm{~mm}$ (Fig. 1b). Overall, it can be concluded that the $50 \%$ coating did not cause any important changes in pellet properties, suggesting that lower coating concentrations would have no such effect either.

\section{In vitro glucose release}

Glucose release was evaluated in pellets coated with Surelease ${ }^{\circledR}$ membrane. Surelease ${ }^{\circledR}$ is an ethylcellulose dispersion pre-plasticized with dibutyl sebacate or coconut oil and stabilized by ammonium oleate. The membrane is insoluble, but semipermeable (15). Since the ethylcellulose membrane is $\mathrm{pH}$-independent, the glucose release of coated pellets was determined in water. Water was already used as a dissolution medium for dosage 


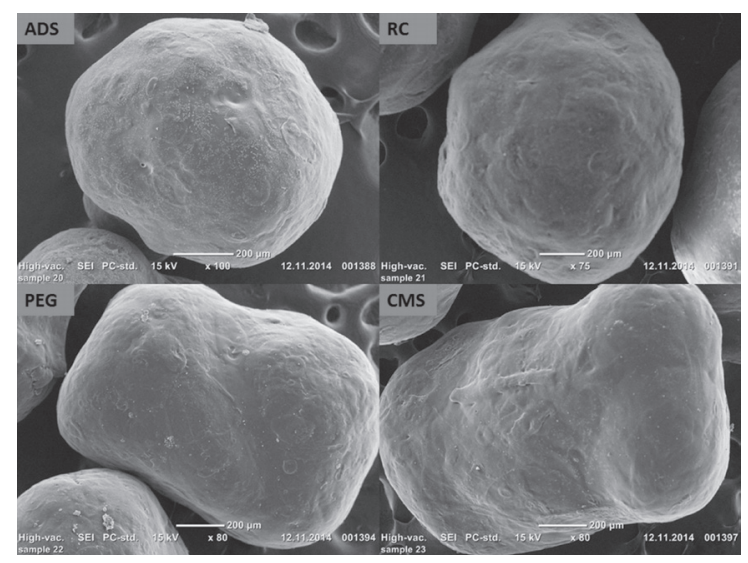

Fig. 3. SEM images of coated pellets.

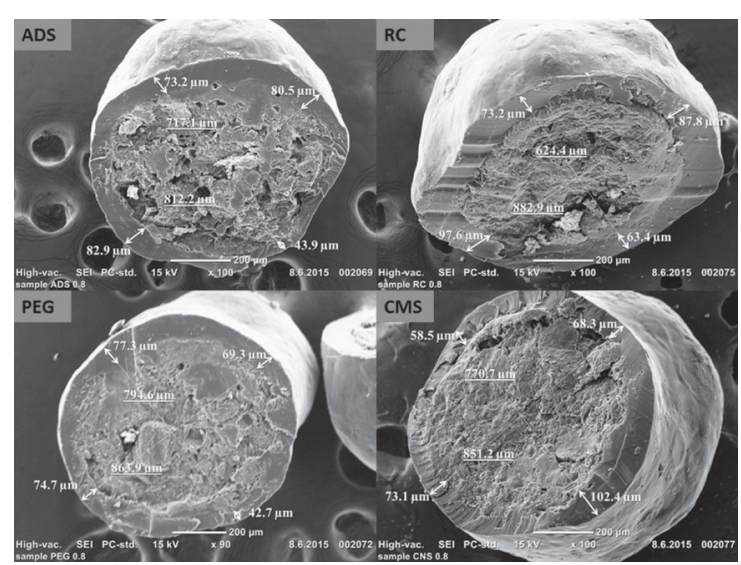

Fig. 4. SEM images of cut pellets. Standard numbers identify the coating thickness, underlined numbers identify the total pellet length.

forms coated with ethylcellulose in various articles $(16,17)$. The experiment was aimed to examine glucose release in the stomach and small intestine. The transit time of pellets into these parts of the gastrointestinal tract is usually 3-7 hours (18). Longer release is therapeutically uninteresting and interrupted by regular diet. Therefore, the length of dissolution was set to 12 hours considering the passage of pellets through the gastrointestinal tract and the required length of lag time. Longer dissolution times would be suitable for studying glucose release in the colon (19). One dissolution profile was acquired for each coating level, resulting in three different profiles for each composition (Fig. 5).

In general, it can be taken that $12.5 \%$ ethylcellulose coating was not suitable for the purpose of this work since the glucose release was immediate in all cases. No lag time was 

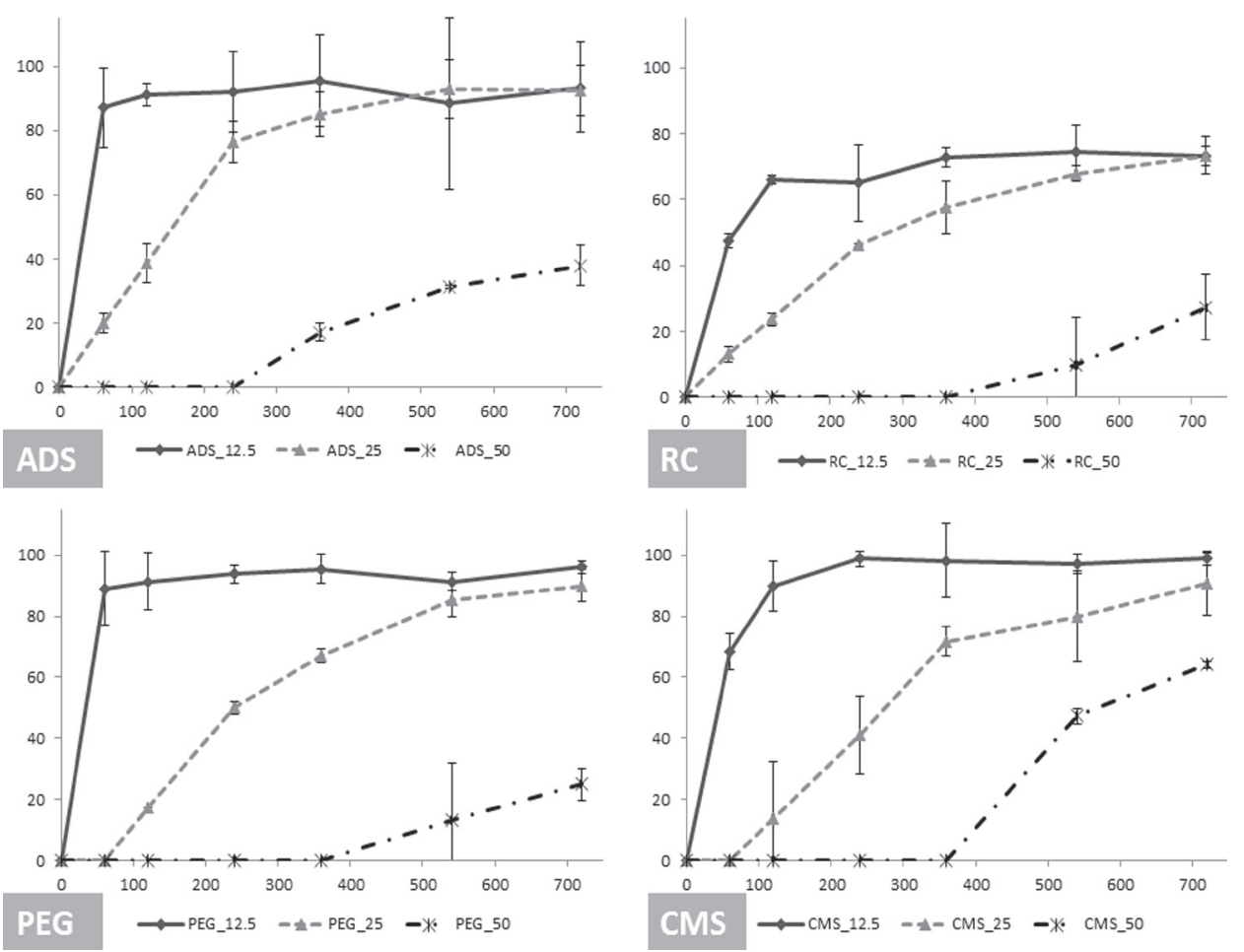

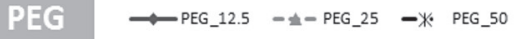

Fig. 5. Dissolution profiles of glucose pellets with different composition and coating concentration. The full line (-) represents $12.5 \%$ coating, the dashed line (- - ) represents $25 \%$ coating, and the dash-dot line (- $\cdot-)$ represents $50 \%$ coating.

observed in $25 \%$ concentrations in ADS and RC samples either. Lag times achieved in PEG and CMS samples were too short for the purposes of this work $(60 \mathrm{~min})$. As observed previously, lag time is represented by the period when the coating is intact and the length of this period is usually based on the coating thickness. The glucose release starts with the formation of coating disruptions (punctures or ruptures) (6). These disruptions develop too early in lower coating concentrations, which is therefore insufficient for the purposes of this work.

Considering the $50 \%$ coating concentration, the glucose release was delayed in all samples with lag times either 240 (ADS) or 360 min (RC, PEG, CMS). Nevertheless, the amount of released glucose was extensively lowered compared to samples with 12.5 and $25 \%$ coating concentrations. The only exception was the CMS sample where the amount of glucose released after the desired lag time was evidently higher than in other samples. Accordingly, it can be presumed that carboxymethyl starch demonstrated the highest swelling ability and water sorption ratio of the excipients used. As water is absorbed into the interior of particle pores, polymer chains expand into a three-dimensional network in which water is retained. Large three-dimensional swelling of carboxymethyl starch par- 
ticles was reported, whereas another superdisintegrant, croscarmellose sodium, is able to swell in three dimensions only partially and its swelling ability is therefore lower (20). Slow release in the PEG sample may be attributed to the osmotic effect of polyethylene glycol, which is probably less effective in higher coating concentrations than the swelling ability of disintegrants. Carboxymethyl cellulose in the RC sample probably slowed down glucose release due to the formation of a gel structure in the initial stages of dissolution (21).

Relations between the compositions, coating concentrations and amounts of released glucose were assessed. In general, increasing coating concentration prolonged the lag time, but extensively lowered the amount of released glucose (ADS, RC, and PEG samples). Considering the dissolution profiles of the CMS sample, the lag time was prolonged from $60 \mathrm{~min}$ ( $25 \%$ coating) to $360 \mathrm{~min}$ (50\% coating), with a sufficient amount of released glucose. It can be assumed that these lag times would also be reached in vivo, since glucose release from the samples containing carboxymethyl starch is unaffected by the change of $\mathrm{pH}$ (22). This suggests that the pellet composition containing carboxymethyl starch is most suitable for the intention of this work and for future use. Therefore, more lag times in the required interval could be presumably achieved by using the same composition and coating concentrations in the $25-50 \%$ range.

\section{CONCLUSIONS}

A dietary supplement for hypoglycemia prevention was successfully prepared in the form of coated pellets with delayed release of glucose. The resulting pellets, which release glucose at clinically suitable time intervals, may be mixed with semi-solid or liquid food or dispersed in a beverage and ingested together with food. Therefore, the patient can administer the dietary supplement a few hours before possible hypoglycemia, e.g., prior to prolonged physical activity or before bedtime. The elevated demand of glucose is subsequently saturated after a defined lag time. In general, it can be concluded that the lag time length is affected not only by the coating concentration, but also by the core composition. Accordingly, the requested lag times can be achieved by a combination of adequate coating concentration and composition. Based on the dissolution profiles, the CMS sample seems to be the most appropriate composition, meeting the basic requirements for the dosage form aimed to prevent hypoglycemia. It can be assumed that pellets with coating concentrations in the range of $25-50 \%$ will probably also release glucose after the desired time interval (120-360 min) and this, along with verifying the results in vivo, could be the scope of further experiments.

Abbreviations. - ADS -croscarmellose sodium, CI - Carr compressibility index, CMS -carboxymethyl starch, HR - Hausner ratio, PEG - polyethylene glycol, RC -Avicel ${ }^{\circledR}$ RC 591, SEM - scanning electron microscopy.

Acknowledgements. - This paper was supported by the project IGA MZ No. 14479/2013 Preparation of a dosage form with controlled release of glucose for the prevention of hypoglycemic states. 


\section{REFERENCES}

1. European Medicines Agency: Committee for Medicinal Products for Human Use, Guideline on clinical investigation of medicinal products in the treatment or prevention of diabetes mellitus, Rev 1, 2012; http://www.ema.europa.eu/docs/en_GB/document_library/Scientific_guideline/2012/06/ WC500129256.pdf; access date May 25, 2015.

2. E. R. Seaquist, J. Anderson, B. Childs, P. Cryer, S. Dagogo-Jack, L. Fish, S. R. Heller, H. Rodriguez, J. Rosenzweig and R. Vigersky, Hypoglycemia and diabetes: a report of a workgroup of the American Diabetes Association and The Endocrine Society Diabetes Care, Diabetes Care 36 (2013) 13841395; DOI: 10.2337/dc12-2480.

3. V. J. Briscoe and S. N. Davis, Hypoglycemia in type 1 and type 2 diabetes: Physiology, Pathophysiology, and Management, Clin. Diabetes 24 (2006) 115-121; DOI: 10.2337/diaclin.24.3.115.

4. C. Kenny, When hypoglycemia is not obvious: Diagnosing and treating under-recognized and undisclosed hypoglycemia, Prim. Care Diabetes 8 (2014) 3-11; DOI: 10.1016/j.pcd.2013.09.002.

5. C. Ryan, N. Gurtunca and D. Becker, Hypoglycemia: A complication of diabetes therapy in children, Pediatr. Clin. North Am. 52 (2005) 1705-1733.

6. A. Franc, J. Muselík, D. Sabadková and D. Neumann, Preparation of pellets with controlled release of glucose as prevention of hypoglycaemia in paediatric patients, Eur. J. Pharm. Sci. 75 (2015) 72-80; DOI: 10.1016/j.ejps.2015.03.007.

7. European Pharmacopoeia, $8^{\text {th }}$ edition, Council of Europe, Strasbourg 2013.

8. M. Rabišková, Technological parameters of drug microforms, their importance and the methods of their determination, Ceska Slov. Farm. 45 (1996) 177-179.

9. F. Podczeck, S. R. Rahman and J. M. Newton, Evaluation of a standardised procedure to assess the shape of pellets using image analysis, Int. J. Pharm. 192 (199) 123-138.

10. R. Chopra, F. Podczeck, J. M. Newton and G. Alderborn, The influence of pellet shape and film coating on the filling of pellets into hard shell capsules, Eur. J. Pharm. Biopharm. 53 (2002) 327-333.

11. C. T. Rhodes and S. C. Porter, Coatings for controlled-release drug delivery systems, Drug Dev. Ind. Pharm. 24 (1998) 1139-1154.

12. H. U. Petereit and W. Weisbrod, Formulation and process considerations affecting the stability of solid dosage forms formulated with methacrylate copolymers, Eur. J. Pharm. Biopharm. 47 (1999) $15-25$.

13. J. Vertomrnen and R. Kinget, The influence of five selected processing and formulation variables on the particle size, particle size distribution, and friability of pellets produced in a rotary processor, Drug Dev. Ind. Pharm. 23 (1997) 39-46.

14. J. Muselík, K. Dvořáčková, K. Krejčová, M. Rabišková, J. Pazourek, S. Marton, M. Dráčková and L. Vorlová, Pellet coating thickness determination by near-infrared reflectance spectroscopy: comparison of two reference methods, Curr. Pharm. Anal. 6 (2010) 225-233; DOI: 10.2174/157341210793 292419.

15. L. A. Felton and J. W. McGinity, Aqueous Polymeric Coatings for Pharmaceutical Dosage Forms, $3^{\text {rd }}$ edition, CMC Press, Boca Raton 2008.

16. F. Sadeghi, J. L. Ford and A. Rajabi-Siahboomi, The influence of drug type on the release profiles from Surelease-coated pellets, Int. J. Pharm. 254 (2003) 123-135; DOI: 10.1016/S0378-5173(03)000036.

17. J. J. Soisa, A. Sousa, M. J. Moira, F. Podczeck and J. M. Newton, The influence of core materials and film coating on the drug release from coated pellets, Int. J. Pharm. 233 (2002) 111-122; DOI: 10.1016/ S0378-5173(01)00921-8.

18. A. Franc, K. Dvořáčková, M. Kejdušová and R. Goněc, Physiological factors with impact on the drug behaviour in the gastrointestinal tract, Ceska Slov. Farm. 62 (2013) 243-248. 
19. S. Milojevic, J. M. Newton, J. H. Cummings, G. R. Gibson, R. L. Botham, S. G. Ring, M. Stockham and M. C. Alwood, Amylose as a coating for drug delivery to the colon: Preparation and in vitro evaluation using glucose pellets, J. Control. Release 38 (1996) 85-94; DOI: 10.1016/0168-3659(95)00113-1.

20. J. Rojas, S. Guisao and V. Ruge, Functional assessment of four types of disintegrants and their effect on the spironolactone release properties, AAPS PharmSciTech. 13 (2012) 1054-1062; DOI: 10.1208/s12249-012-9835-y.

21. M. Rabišková, A. Häring, K. Minczingerová, M. Havlásek and P. Musilová, Microcrystalline cellulose in oral dosage forms, Chem. Listy 101 (2007) 70-77.

22. A. Franc, D. Sabadková, D. Neumann, S. Pavloková, Kopecká and P. J. Muselík, Interdiction of hypoglycemia in diabetic children by multiparticulate dosage form with controlled glucose release, Pharm. Dev. Technol. 3 (2015) 1-8. 